\title{
High Temperature Variable Conductance Heat Pipes for Radioisotope Stirling Systems
}

\author{
Calin Tarau, Kara L. Walker and William G. Anderson \\ Advanced Cooling Technologies, Inc. \\ 1046 New Holland Ave. \\ Lancaster, PA 17601 U.S.A. \\ 717-295-6104; Bill.Anderson@1-ACT.com
}

\begin{abstract}
In a Stirling radioisotope system, heat must continually be removed from the GPHS modules, to maintain the GPHS modules and surrounding insulation at acceptable temperatures. Normally, the Stirling convertor provides this cooling. If the Stirling convertor stops in the current system, the insulation is designed to spoil, preventing damage to the GPHS, but also ending the mission. An alkali-metal Variable Conductance Heat Pipe (VCHP) is under development to allow multiple stops and restarts of the Stirling convertor. The status of the ongoing effort in developing this technology is presented in this paper. An earlier, preliminary design had a radiator outside the Advanced Stirling Radioisotope Generator (ASRG) casing, used NaK as the working fluid, and had the reservoir located on the cold side adapter flange. The revised design has an internal radiator inside the casing, with the reservoir embedded inside the insulation. A large set of advantages are offered by this new design. In addition to reducing the overall size and mass of the VCHP, simplicity, compactness and easiness in assembling the VCHP with the ASRG are significantly enhanced. Also, the permanently elevated temperatures of the entire VCHP allows the change of the working fluid from a binary compound $(\mathrm{NaK})$ to single compound $(\mathrm{Na})$. The latter, by its properties, allows higher performance and further mass reduction of the system. Preliminary design and analysis shows an acceptable peak temperature of the ASRG case of $140^{\circ} \mathrm{C}$ while the heat losses caused by the addition of the VCHP are $1.8 \mathrm{~W}$.
\end{abstract}

Keywords: Alkali Metal Heat Pipes, Variable Conductance Heat Pipes, Radioisotope Stirling Systems, Nak Heat Pipes, Advanced Stirling Radioisotope Generator, Space Radiator Systems

PACS: $44.30 .+v, 44.35 .+c$.

\section{INTRODUCTION}

This paper presents the design of a Variable Conductance Heat Pipe (VCHP) that will provide backup cooling for the Advanced Stirling Radioisotope Generator (ASRG). In a Stirling radioisotope power system, one or more General Purpose Heat Sources (GPHS) modules supply heat to a Stirling convertor. This heat is used to generate electric power, and the waste heat is radiated to space. In a GPHS, the radioisotope plutonium-238 (Pu-238) used to produce the heat is encapsulated into an iridium cladding forming a fueled clad. The fueled clads are surrounded by graphite. The maximum allowable GPHS module operating temperature is set by the iridium cladding around the $\mathrm{Pu}-238$ fuel. The GPHS module is designed so that it will not release plutonium, even under such postulated events as a rocket explosion, or reentry from earth orbit. However, if the iridium cladding is overheated, grain boundary growth can weaken the cladding, possibly allowing plutonium to be released during an accident.

Heat must continually be removed from the GPHS modules, to maintain the GPHS modules and surrounding insulation at acceptable temperatures. Normally, the Stirling convertor removes the heat, keeping the GPHS modules cool. There are three basic times when it may be desirable to stop and restart the Stirling convertor: 1) During installation of the GPHS, 2) During some missions, to minimize electromagnetic interference and vibration while taking scientific measurements, and 3) Possible restart after an unexpected stoppage. Without the VCHP, any stoppage of the convertor during operation on the ground or during a mission could cause the insulation to spoil to 
protect the GPHS. The VCHP would allow convertor operation to be restarted, depending on the reason for stoppage. It would also save replacing the insulation after such an event during ground testing.

The schematics in Figures 1a and b show the basic concept of the VCHP integrated with a Stirling convertor. The evaporator of the VCHP is in contact with the GPHS module through the heat collector. The non-condensable gas (NCG) charge in the system is sized so the secondary condenser is blocked during normal operation and the VCHP delivers heat to the heater head through the condensing surface: see Figure 1a. When the Stirling convertor is stopped, the temperature of the entire system starts to increase. Since the VCHP system is saturated, the working fluid vapor pressure increases as the temperature increases. This compresses the NCG. As shown in Figure 1b, this opens up the secondary condenser. Once the condenser (condensing surface) is fully open, all of the heat is dumped to the radiator, and the temperature stabilizes. Once the Stirling convertor starts operating again, the vapor temperature and pressure start to drop. The non-condensable gas blankets the condenser, and the system is back to the normal state (Figure 1a).

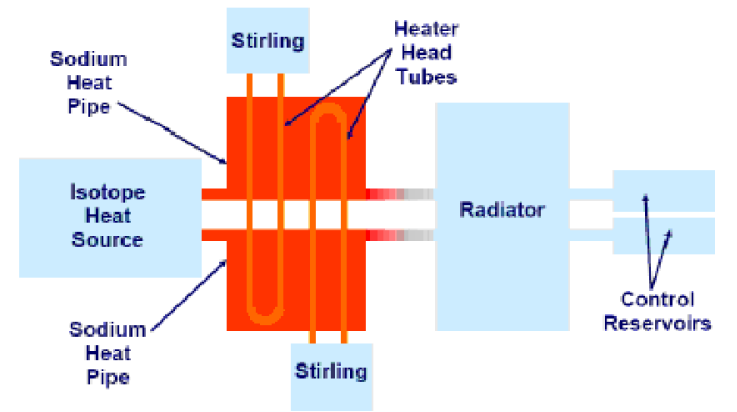

(a)

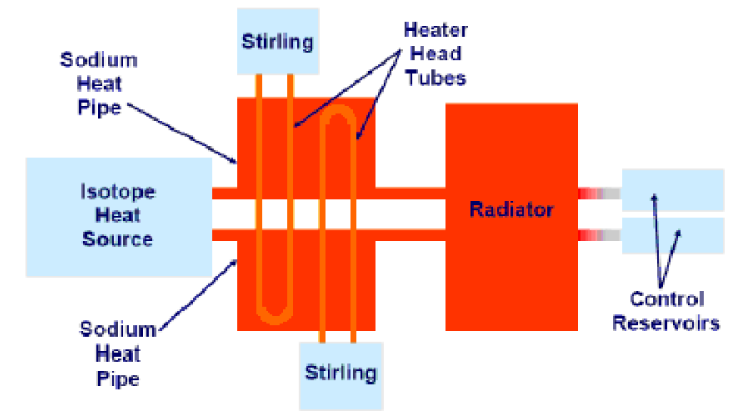

(b)

FIGURE 1. Stirling convertor (a) operating and (b) stopped.

\section{VCHP REQUIREMENTS}

The ASRG (Chan, Wood, and Schreiber, 2007) was selected as the baseline design. The system consists of two Advanced Stirling Converters (ASCs), mounted back to back to minimize vibration. Heat to each ASC is supplied by one GPHS module. During operation, a heat collector is used to conduct the heat from the GPHS into the Stirling heater head (Figure 2a). A cold-side adapter flange, shown in Figure $2 b$ is used to conduct the waste heat from the Stirling convertor cold side to the ASRG housing. This is fabricated from copper, and serves as a structural member. The cold-end flange temperature is primarily set by the sink temperature seen by the ASRG structure (radiator), which varies from earth (including launch) environments to deep space. Its operating temperature can range from 40 to $120^{\circ} \mathrm{C}$, depending on the radiation environment that the ASRG sees. During ASC stoppage, this temperature range can drop significantly.

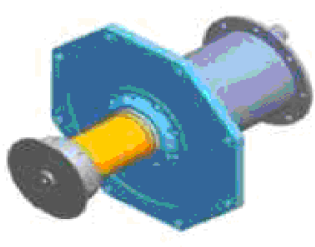

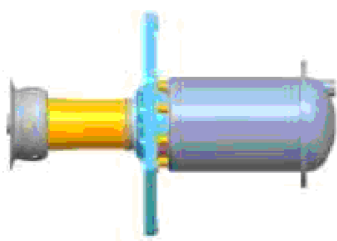

(a)

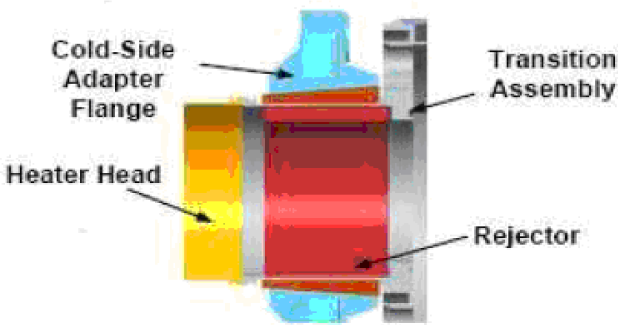

(b)

FIGURE 2. (a) Stirling Convertor with Heat Collector and Cold-Side Adapter Flange and (b) Cold-Side Adapter Flange (Chan, Wood, and Schreiber, 2007). 
The heater head hot-end temperature was assumed to be $850^{\circ} \mathrm{C}$ for this program, compared to the current ASRG engineering unit temperature of $650^{\circ} \mathrm{C}$. To accommodate this increase, the heater head material in the ASC/ASRG project was changed from the Inconel 718 used in the ASRG engineering unit to Mar-M 247. Mar-M 247 is a nickel-based casting alloy designed to have good tensile and creep rupture properties at elevated temperatures. A summary of the initial design requirements is presented below in Table 1.

TABLE 1. VCHP Design Requirements.

\begin{tabular}{lc}
\hline GPHS Power $(\mathrm{W})$ & 250 \\
GPHS Power to the Stirling Convertor $(\mathrm{W})$ & 225 \\
Heater Head Temperature $\left({ }^{\circ} \mathrm{C}\right)$ & 850 \\
Heater Head Material & Mar-M 247 \\
Conduction Losses down the Heater Head Wall $(\mathrm{W})$ & 6.5 \\
Heat Collector Material (Baseline) & Nickel 201 \\
Potential Reservoir Location & Cold-Side Adapter Flange \\
Cold-Side Adapter Flange Temp. $\left({ }^{\circ} \mathrm{C}\right)$ & 40 to 120 \\
Heat Pipe Working Fluid & Sodium or NaK \\
VCHP Temperature when Stirling is Off $\left({ }^{\circ} \mathrm{C}\right)$ & 880 \\
\hline
\end{tabular}

\section{VCHP DESIGN}

As shown earlier (Anderson and Tarau, 2008; Tarau, Anderson and Walker, 2008), a non-integrated system was selected where the VCHP wraps around the heat collector (rather than replacing the heat collector as required by an integrated system). In the preliminary design, the VCHP had a condenser and radiator that were external to the ASRG case. The reservoir location was on the upper side of the CSAF where, as stated above, the temperature can fluctuate between 40 and $120^{\circ} \mathrm{C}$ during the ASRG operation. The revised design has the condenser located inside the ASRG case, with the reservoir embedded in the insulation; see Figure 3.

\section{VCHP working conditions}

Normally, when the ASC is working, heat is transferred from the GPHS to the ASC. Most of this heat is transferred to the heater head through the heat collector; see Figure 3. Within the heat collector, heat follows two paths, one directly through the heat collector (Nickel 201) while the other path passes through the VCHP, evaporating and condensing the working fluid at the "Evaporating Surface" and "Condensing Surface" (Figure $3 \mathrm{~b}$ ), respectively. Consequently, the presence of the VCHP with the isothermal vapor decreases the temperature non-uniformities at the heat collector - heater head interface. This is an additional benefit because it increases the ASC efficiency, and extends the heater head life.

In normal conditions, when the ASC is ON, the system is operated so that the nominal heater head temperature is $850^{\circ} \mathrm{C}$ (including the VCHP working fluid vapor). The VCHP is designed and charged with NCG so that the vapor pressure at the operating temperature keeps the vapor - NCG interface (front) somewhere between locations 1 and 2 (Figure 3b) while the condenser is blocked by NCG. Locations 1 and 2 are determined by the maximum and minimum temperatures of the reservoir when the ASC is working. Initially, when the reservoir was located on the upper side of the CSAF, these temperatures were 120 and $40^{\circ} \mathrm{C}$ respectively. Because of the new reservoir location (within the insulation - Figure 3a) this temperature interval has changed. In fact two reservoir temperature intervals are present now, a cold one (when ASC is ON) and a hot one (when ASC is OFF). As discussed below, these temperature intervals are a key consideration for the VCHP design.

When the ASC stops working and the GPHS is no longer cooled, the GPHS, heat collector, heater head, and VCHP increase in temperature. Since the working fluid in the VCHP is at saturation conditions, the vapor pressure also increases and pushes the non-condensable gas front toward the internal condenser and radiator. When vapor temperature reaches $880^{\circ} \mathrm{C}$ the front is at equilibrium somewhere between locations 3 and 4 , so that the secondary condenser surface is supplied with hot vapor. The GPHS heat is now directed to the internal condenser and radiator. The heat is radiated to the internal face of the ASRG case. It is then spread by the case, and radiated from the case to the environment. A radiator was chosen instead of a direct connection to the case to minimize losses when the ASC is off. When the ASC starts working again, vapor temperature resettles at $850^{\circ} \mathrm{C}$ while the front returns 
between locations 1 and 2 (corresponding to the cold reservoir temperature range) allowing the NCG to block the condenser again.

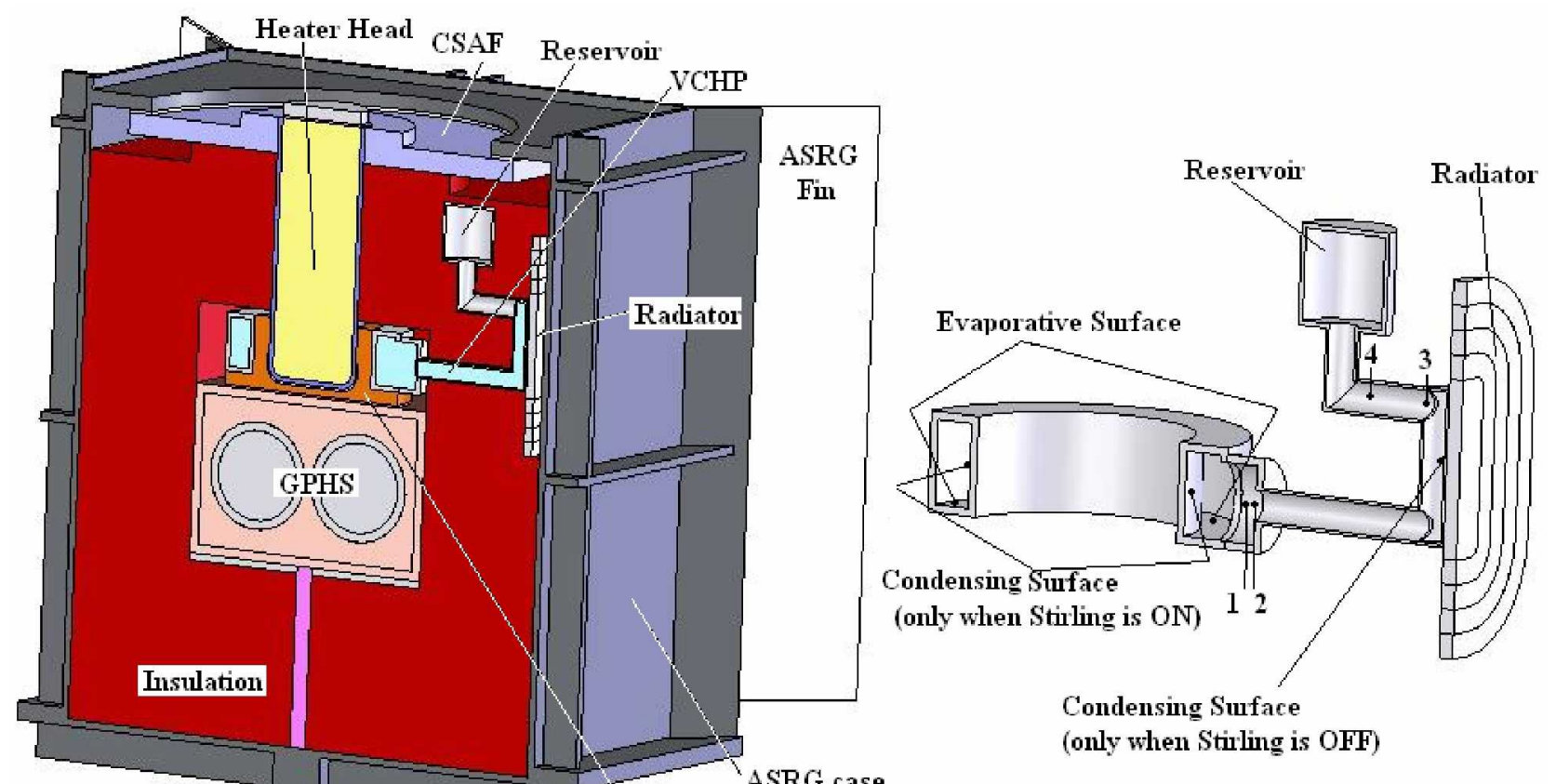

(a)

Heat Collector

FIGURE 3. (a) VCHP installed in the ASRG and (b) VCHP detail. The VCHP design has internal condenser and reservoir embedded in the insulation.

\section{Thermal Analysis}

The first step in modeling the ASRG was to develop a thermal model without a VCHP installed. The geometry and materials were taken from the publically available data. Thermal interfaces were simulated by thermal resistances whose properties (mainly thermal conductivity) were adjusted iteratively until the temperature profiles and heat losses distributions matched the approximate ones provided by NASA. This baseline model was then used to for thermal analyses with the VCHP installed. The objectives of these analyses were:

- Validate the VCHP model

- Find temperature distributions and heat leaks within the new ASRG configuration (with the VCHP installed)

- Evaluate the two reservoir temperature ranges at the new location with the Stirling (ASC) ON and OFF.

- Size the internal radiator

- Find the temperature distribution on the ASRG case.

Four different cases were investigated (Table 2). The highest temperature level (case C) was evaluated for ASC OFF, where the GPHS delivered a maximum power of $250 \mathrm{~W}$, corresponding to the Beginning of Mission (BOM) and the heat sink temperature was $293 \mathrm{~K}$ (terrestrial environment). Similarly the lowest temperature level (case B) was evaluated for ASC ON, where the GPHS delivered the minimum power of $225 \mathrm{~W}$ corresponding to the End of Mission (EOM) and the heat sink temperature was only $4 \mathrm{~K}$ (deep space). While these two extreme cases determine the upper and the lower limits of the hot and cold reservoir temperature intervals respectively (cases $\mathrm{C}$ and $\mathrm{B}$ ), the other two cases determine the lower and the higher limits of hot and cold reservoir temperature intervals respectively (cases $\mathrm{A}$ and $\mathrm{D}$ ). 
TABLE 2. VCHP_ASRG system analysis matrix.

\begin{tabular}{lcc}
\hline & BOM radiating to terrestrial environment & EOM radiating to Deep Space \\
\hline ASC ON & A & B \\
ASC OFF & C & D \\
\hline
\end{tabular}

The boundary conditions used in the model include:

- GPHS heat generation rate of 250W for BOM and 225W for EOM.

- Electric output of $90 \mathrm{~W}$ for BOM and $84 \mathrm{~W}$ for EOM.

- Sink temperatures of 293K (terrestrial) and 4K (deep space).

- External emissivity of 0.8 .

- Internal radiator has an emissivity of 0.8 and radiates only through the side facing the ASRG case.

- All other internal surfaces were insulated.

- Two symmetry planes (indicated below in Figure 4a).

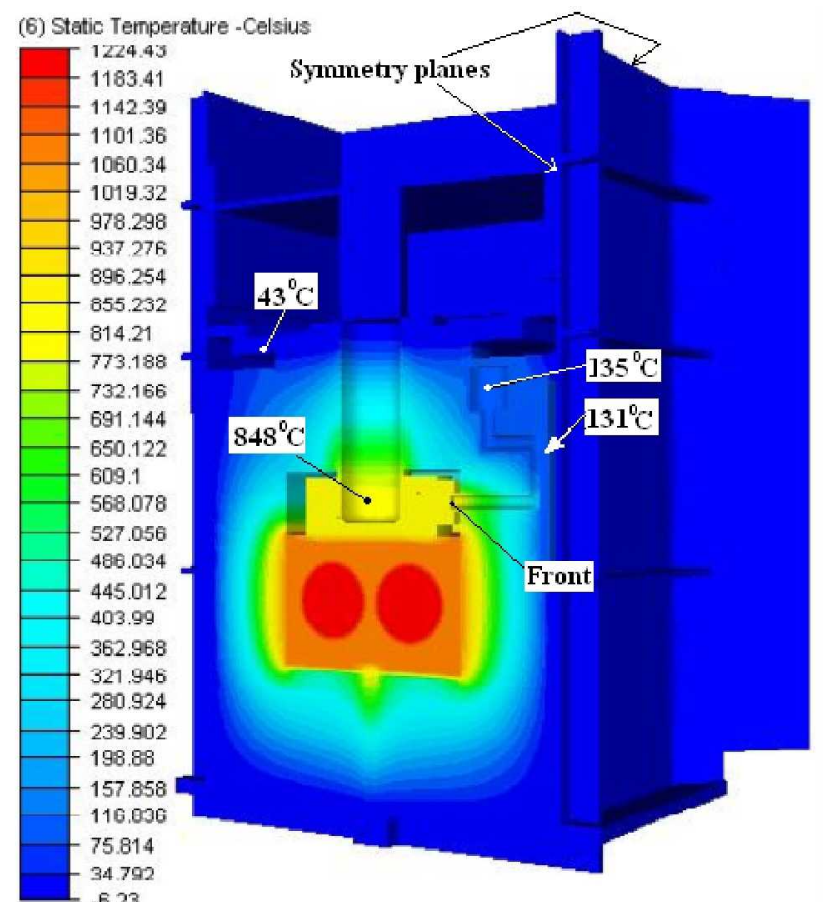

(a)

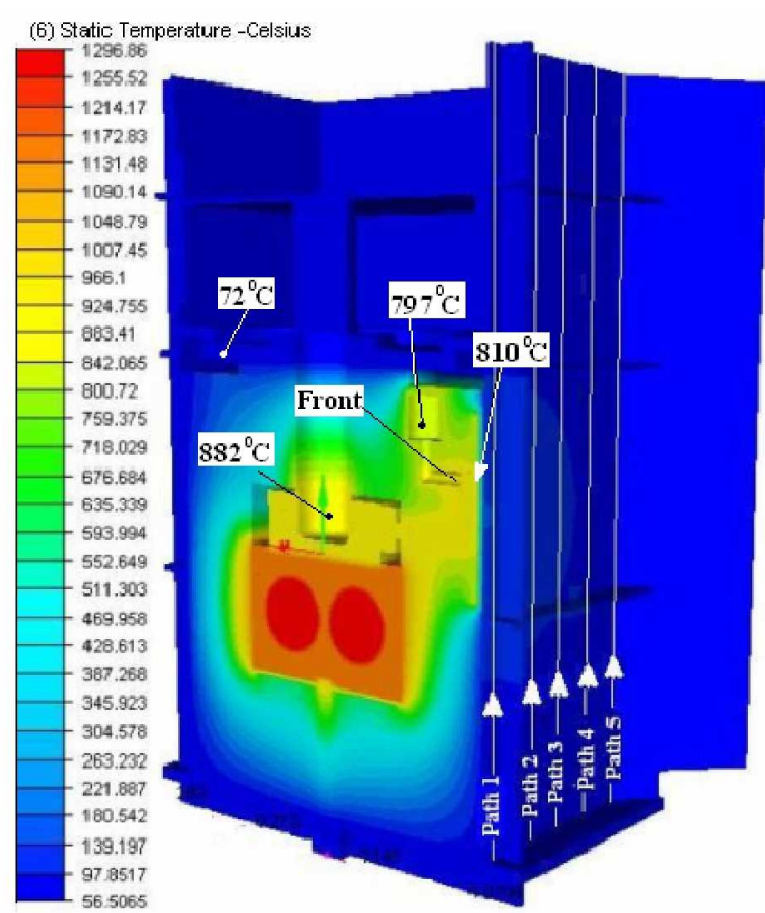

(b)

FIGURE 4. VCHP-ASRG system thermal analysis (a) case B - ASC ON, EOM, heat sink is deep space. (coldest case) b) case C - ASC OFF, BOM, heat sink is terrestrial environment (hottest case).

Steady state temperature distributions for the coldest and hottest cases (B and C, respectively) are shown in Figure 4. The coldest case (case B) shows minimum temperatures of $848^{\circ} \mathrm{C}$ for vapor and $135^{\circ} \mathrm{C}$ for reservoir. Similarly, the hottest case (case C) shows maximum temperatures of $882^{\circ} \mathrm{C}$ for vapor and $797^{\circ} \mathrm{C}$ for reservoir. The two front locations $(1-2)$ and $(3-4)$ are shown on the plots. The difference between the two vapor temperatures is approximately equal to the temperature difference necessary to push the front from locations $(1-2)$ to locations $(3-$ 4) and activate the internal radiator. Also, it can be observed on Figure 4a that the CSAF temperature is approximately $43^{\circ} \mathrm{C}$ which corresponds to the lower side of the temperature interval specified by the design requirements. The temperature of the CSAF corresponding to case $\mathrm{A}$ is $117^{\circ} \mathrm{C}$, so these results correspond closely to the expected temperature range of 40 to $120^{\circ} \mathrm{C}$. These temperatures together with the heater head temperature of $848^{\circ} \mathrm{C}$ with the Stirling convertor ON (design value of $850^{\circ} \mathrm{C}$ ) and the heater head temperature of $882^{\circ} \mathrm{C}$ when the Stirling convertor is $\mathrm{OFF}$ (design value of $880^{\circ} \mathrm{C}$ ) also validate the model. Heat leaks are also within the prescribed 
values. One important heat leak is the one caused by the presence of the VCHP. It was evaluated by both using the actual geometry of the pipe together with the temperature gradient along the pipe depicted in Figure 5 (cases A and B) and the radiated heat to the inside of the case. It was determined that in both cases, A and B (Stirling ON), the heat conducted by the VCHP walls did not exceed $1.8 \mathrm{~W}$ while heat radiated to the internal casing did not exceed $0.9 \mathrm{~W}$. The first one is conservatively considered. Also, the radiator size was determined from iterative adjustments to radiate at the desired rate.

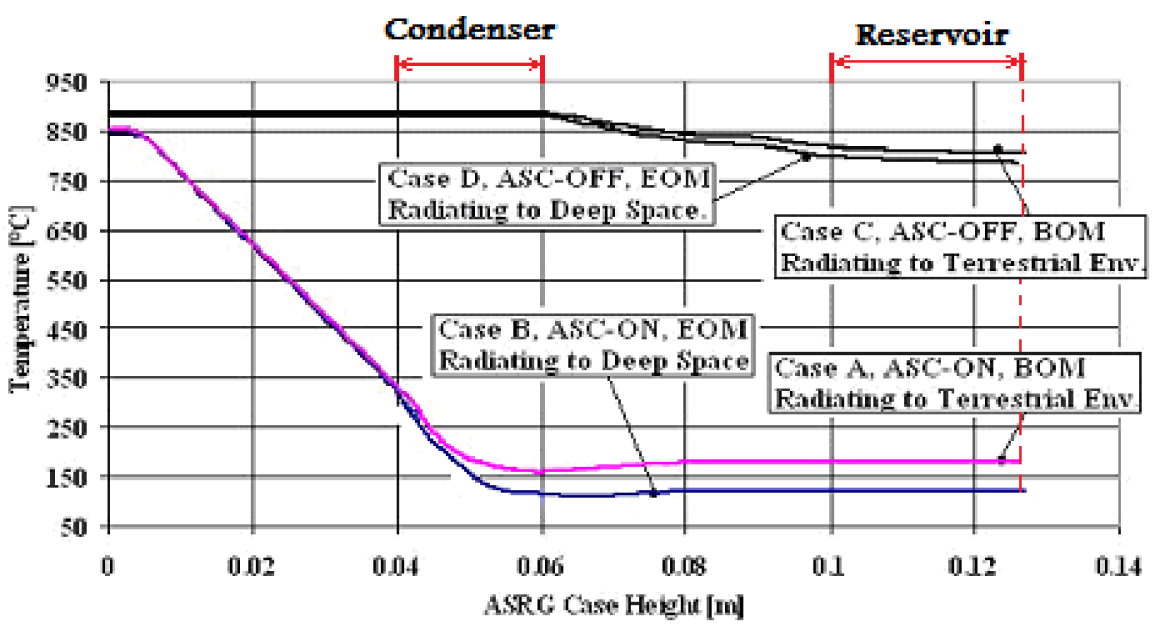

FIGURE 5. Temperature distributions along the entire VCHP for all four cases.

Figure 5 shows the temperature distributions along the VCHP walls for all four cases. The distance shown on the abscissa starts at the VCHP evaporator. Cases A and B show a relatively constant temperature gradient between the evaporator and the condenser. As mentioned before, this gradient was used to evaluate the heat leaks through the VCHP's walls. Also for these two cases (when ASC is ON), temperature differences between condenser and reservoir show negligible values suggesting minimum heat leaks due to the reservoir embedment into the insulation. Cases C and D (ASC is OFF) show an elevated flat temperature profile between the evaporator and the end of condenser that is the actual vapor temperature. As seen, most of the heat is dumped into the condenser and radiator; however, the mild temperature gradient between condenser and reservoir shows that a small heat leak toward the reservoir exists. The two temperature ranges of the reservoir are evaluated as $135^{\circ} \mathrm{C}-189^{\circ} \mathrm{C}$ for the cold case (ASC $\mathrm{ON}$ ) and $785^{\circ} \mathrm{C}-797^{\circ} \mathrm{C}$ for the hot case (ASC OFF). The NCG temperatures are also determined for all sections.

Since with an internal radiator design, the housing walls will radiate the entire power delivered by the GPHS (when ASC is OFF) to the environment, the temperature distribution on the main radiating wall was investigated for the most severe case, $\mathrm{C}$.

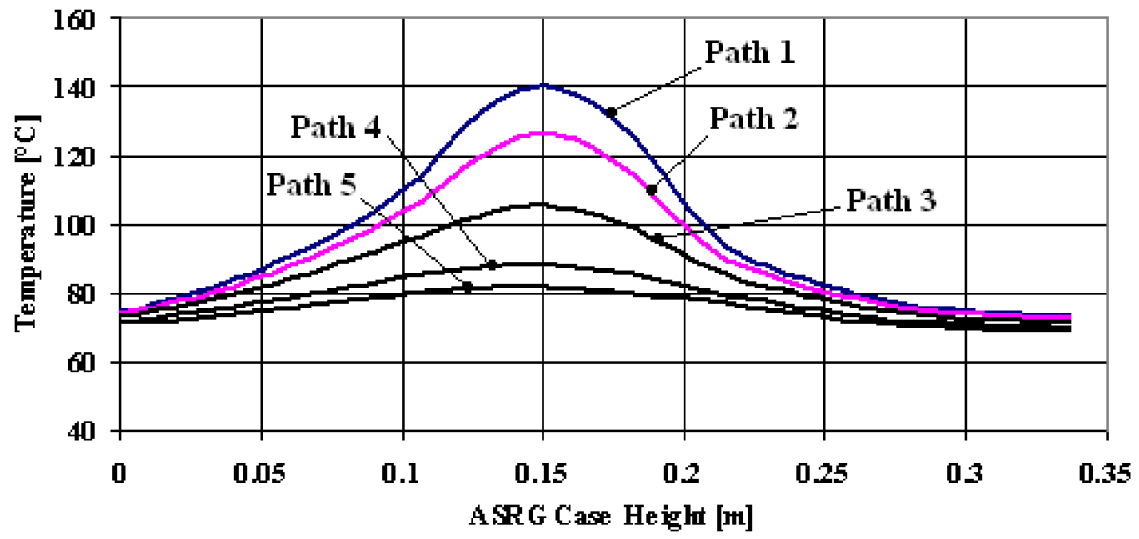

FIGURE 6. VCHP-ASRG thermal analysis results of the main radiating wall. The five paths for temperature profile evaluation are shown above in Figure 4b. 
Figure 6 shows the temperature profiles on the housing's main radiating wall measured along the five paths presented in Figure $4 \mathrm{~b}$. The abscissa represents the height of the ASRG starting from the bottom and ending at the centerline of the ASRG. As seen the temperature peak is about $140^{\circ} \mathrm{C}$ and is located at the intersection between the internal radiator's central axis and the external surface of the ASRG side wall. The value of this peak can be significantly reduced by an optimized case thickness in the radiated region; however the actual thermal field is already acceptable.

\section{Advantages}

This configuration with an internal condenser and the reservoir embedded in the insulation offers multiple advantages over an external radiator design:

- By removing the external radiator, the entire VCHP system becomes less complicated. The issues connected to sealing systems for the wall penetrations and space debris exposure of the panel, are no longer present. Also, the external configuration of the ASRG system is not affected.

- Technological issues regarding the assembling of the VCHP with the ASRG are no longer present. Also, by radiating to the internal wall and removing the direct contact between the VCHP and the housing wall, thermal stresses are avoided.

- The new temperatures of the reservoir are much higher, ranging between 135 and $797^{\circ} \mathrm{C}$, depending on the ASRG working parameter configuration. This range could be adjusted as a function of the location of the reservoir within the insulation. The connecting pipe is also exposed to higher temperatures than before since it is also embedded in the insulation. For the external radiator design, $\mathrm{NaK}$ was the only option as a working fluid mainly due to its low freezing point. In the new design, sodium or potassium could also be selected as the working fluid as shown in Table 3. Despite its freezing point, which is the highest among all four compounds, sodium is the best choice because of the following reasons:

- Temperature through the entire system will be always higher than the freezing point.

- Sodium has the highest surface tension; it doubles the capillary pumping capability compared to $\mathrm{NaK}$.

- Sodium has the lowest vapor pressure; it allows thinner walls creating other two benefits: a lighter system and a higher thermal resistance to reduce heat leaks.

- Sodium has the highest latent heat; it allows a higher performance limitation and, hence, higher performance factor of safety because of the lower pressure drop through the porous structure. It also creates the conditions for a smaller cross-section area of the wick which means smaller diameters and consequently lower mass.

- Liquid viscosity of sodium is $20 \%$ higher than NaK's, however, each of the other three properties mentioned above has, by far, a greater beneficial effect.

- Sodium is a single species compound; the issues connected to the temperature non-uniformities developed by the two species compound $(\mathrm{NaK})$ no longer exist. Also, the diffuse front modeling simplifies from a three species model ( $\mathrm{Na}, \mathrm{K}$ and NCG) to a two species model (Na and NCG). This is less complicated than before when three species diffusion had to be simulated.

- The overall system becomes smaller in size just because of the reduced distances. The additional consequences are:

- Both gravitational pressure head and wick pressure drop decrease allowing for a higher performance factor of safety.

- Again, wick structure will have smaller cross-section area and, hence, smaller diameters will be required. This will lead to mass reduction because off both smaller diameters and smaller lengths.

This design is able to perform gravity independent and is significantly lighter. The minimum performance factor of safety (FOS) is 4.2. Based on the feedback from NASA and Lockheed Martin the design was selected as a baseline. Based on these results further iterations and development are being performed. 
TABLE 3. Sodium, Potassium, Cesium, and NaK Fluid Properties at $850^{\circ} \mathrm{C}$.

\begin{tabular}{ccccc}
\hline Property $/$ Fluid & $\mathrm{Na}$ & $\mathrm{K}$ & $\mathrm{Cs}$ & $\mathrm{NaK}$ \\
\hline Melting Temperature, $\left({ }^{\circ} \mathrm{C}\right)$ & 97.8 & 63.2 & 28.4 & -12.7 \\
Boiling Temperature, $\left({ }^{\circ} \mathrm{C}\right)$ & 881.4 & 756.5 & 668.4 & 785 \\
Vapor Pressure, $(\mathrm{KPa})$ & 75.99 & 222.9 & 432.65 & 175.29 \\
Surface Tension, $(\mathrm{N} / \mathrm{m})$ & 0.121 & 0.058 & 0.030 & 0.067 \\
Liquid Viscosity, $(\mathrm{Pa}-\mathrm{s})$ & 0.000162 & 0.000116 & 0.000138 & 0.000129 \\
Latent Heat, $(\mathrm{MJ} / \mathrm{kg})$ & 4.41 & 2.05 & 0.50 & 2.57 \\
\hline
\end{tabular}

\section{CONCLUSIONS}

A new design configuration for the VCHP as a backup cooling system for the Advanced Stirling Radioisotope Generator (ASRG) was developed. Two significant changes were made: the condenser is located inside the ASRG (radiating to the internal surface of the housing wall), and the reservoir is located inside the insulation, slightly under the cold side adapter flange. Many important benefits resulted from these configuration modifications. The ASRG case now is the only radiator and no wall penetrations are needed. The system is much simpler and compact. A significant mass reduction and an increase in the performance factor of safety are obtained. Better reservoir temperature control is expected. The overall temperatures of the VCHP system are higher and potential freezing of the working fluid at any time is no longer a risk. Consequently, a very important change now is possible: NaK can be replaced by $\mathrm{Na}$ as the working fluid. The single species compound is superior to $\mathrm{NaK}$ through the following properties: higher surface tension, lower vapor pressure and higher latent heat. Using $\mathrm{Na}$ as the working fluid, further mass reduction and performance improvement will result. Also, temperature non-uniformities at evaporation and condensation interfaces because of the binary nature of $\mathrm{NaK}$, investigated and discussed in previous papers, are eliminated.

A preliminary thermal analysis of the VCHP - ASRG system shows that the peak temperature of the radiating wall surface would be approximately $140^{\circ} \mathrm{C}$. This temperature can be further reduced by optimizing heat spreading at the wall. It was also observed that embedding the reservoir inside the insulation, the insulation efficiency is not altered. The presence of the VCHP generates an acceptable $1.8 \mathrm{~W}$ heat leak. The two reservoir temperature ranges, cold and hot, are $135^{\circ} \mathrm{C}-189^{\circ} \mathrm{C}$ (ASC ON) and $785^{\circ} \mathrm{C}-797^{\circ} \mathrm{C}$ (ASC OFF) respectively.

\section{ACKNOWLEDGMENTS}

This research was sponsored by NASA Glenn Research Center under Contract No. NNC07QA40P. Lanny Thieme was the technical monitor. We would like to thank Jeff Schreiber and Jim Sanzi of NASA Glenn Research Center and Jack Chan of Lockheed Martin Space Systems Company for helpful discussions about the Stirling system and the VCHP. We would like to thank Roy Tew of NASA Glenn Research Center for running cases with the Sage Stirling thermodynamic code to estimate the effects of isothermalizing the heater head with the VCHP.

\section{REFERENCES}

Anderson, W. G., Tarau, C., "Variable Conductance Heat Pipes for Radioisotope Stirling Systems," in the proceedings of Space Technology Applications and International Forum (STAIF-08), edited by M.S. El-Genk, AIP Conference Proceedings 969, Melville, NY, (2008).

Chan, T.S., Wood, J. G. and Schreiber, J. G., "Development of Advanced Stirling Radioisotope Generator for Space Exploration," NASA Glenn Technical Memorandum, NASA/TM-2007-214806, (2007).

Tarau, C., Anderson, W. G., and Walker, K., "NaK Variable Conductance Heat Pipe for Radioisotope Stirling Systems", IECEC, Cleveland, OH, July 28-30, (2008). 